\title{
Resenha: Psicologia, Organizações e Trabalho no Brasil
}

\author{
Jaques-Jesus ${ }^{1}$ \\ Universidade de Brasília
}

\section{Book Review: Psychology, Organizations and Work in Brazil}

O livro Psicologia, Organizações e Trabalho no Brasil (Zanelli, Borges-Andrade \& Bastos, 2004) é o produto da colaboração entre a experiência e o conhecimento de vários autores que pesquisam as organizações e o trabalho, nacional e internacionalmente. Desde a sua publicação, revela-se como um handbook essencial para a compreensão da história, do contexto, dos temas atuais e perspectivas da Psicologia Organizacional e do Trabalho em território nacional.

É importante ressaltar que as pesquisas acerca da categoria trabalho são fundamentais para o conhecimento e a transformação da realidade brasileira, na qual demandas sociais requerem a produção de conhecimentos científicos aplicáveis às organizações. Nesse sentido, a contribuição de profissionais com práticas e saberes nativos, que respondam às peculiaridades brasileiras, pode ser entendida como um compromisso ético.

Vale lembrar que a Psicologia Transcultural critica a Psicologia Organizacional e do Trabalho em razão da sua tendência a assumir o viés ocidental do corpus teórico e da metodologia das metrópoles econômicas (Bhagat, Kedia, Harveston \& Triandis, 2002; Schaubroeck \& Lam, 2002; Torres \& Ferdman, no prelo; Van der Vijver \& Leung, 2000), em especial estadunidenses, o que prejudica a fidedignidade das pesquisas, além de menosprezar a consistente base empírico-conceitual nacional caracterizada, como indicam Faria e Alencar (1996), por elevado grau de criatividade, apesar da exigüidade de recursos tecnológicos avançados e de suporte estrutural.

Foi meta dos autores de Psicologia, Organizações $e$ Trabalho no Brasil reunir profissionais acadêmicos em torno do objetivo comum de viabilizar ações significativas, relevantes e auto-realizadoras. Desse modo, os capítulos foram articulados segundo temas cruciais relativos ao trabalho nas organizações. Uma breve descrição de alguns deles pretende demonstrar a importância do conjunto, constituindo-se em um incentivo à leitura e ao estudo da obra completa.

Em O Mundo do Trabalho, Borges e Yamamoto delineiam uma mito-história do trabalho, entendido pelos antigos romanos como tripalium, trabicula - um tipo de tortura - passando por Marx, que concebeu o valor intrínseco da intencionalidade no produto do trabalho humano. O modelo tayloristafordista é criticado em função de seu esgotamento frente aos novos paradigmas laborais. Este capítulo configura-se como uma instigante introdução ao livro; ao movimentar-se habilmente através de referências literárias, históricas e filosóficas, analisando as dimensões do trabalho com profundo conhecimento e reflexão.

1 Endereço: SQN 210 Bloco H ap. 109, Brasília, DF, Brasil 70862-080. E-mail: jaques@unb.br
Conceito e Perspectivas de Estudo das Organizações, de Bastos e cols., separa as definições de organizações do senso comum das do campo científico, explorando a importância do conceito nas visões propostas: cognitivista, culturalista, institucionalista e neo-institucionalista (abordagens francesa e anglo-saxônica). As principais dimensões do conceito de organização são sintetizadas. Neste capítulo, os autores realizam uma elaborada síntese do que são as organizações como produtos do trabalho humano, o que deve ser levado em conta como um importante suporte teórico para a formulação de estratégias para as organizações contemporâneas, caracterizadas pela progressiva complexidade de sua dinâmica.

Com Aprendizagem Humana em Organizações de Trabalho, Abbad e Borges-Andrade definem aprendizagem e competências, aprofundando-se, a partir das teorias de aprendizagem, no detalhamento dos sistemas de classificação e hierarquização de resultados de aprendizagem, abordando, ainda, os domínios de aprendizagem de Bloom (cognitivo, afetivo e psicomotor) e as categorias de capacidades humanas treináveis de Gagné (habilidades intelectuais, informação verbal, estratégias cognitivas, habilidades motoras e atitudes). O capítulo reproduz, na sua própria estrutura, o tema que aborda, voltando-se para a modificação do comportamento do leitor e assinalando a importância da compreensão do fenômeno da aprendizagem para as organizações e as condições para a sua efetividade.

Em Saúde Mental e Trabalho, Codo e cols. apontam a indispensabilidade da Psicologia na explicação e intervenção sobre os fatores de saúde do trabalhador "invisíveis" à fisiologia e à bioquímica médicas. Esses fatores são ressaltados pelas particularidades dos casos, que se desdobram no contexto das teorias de estresse, psicodinâmica do trabalho e abordagem epidemiológica e/ou diagnóstica.

Socialização Organizacional, de Borges-Andrade e Albuquerque, disserta acerca do processo organizacional de aprendizagem da cultura, dos valores, dos objetivos, das estratégias de contato interpessoal - processo entendido de modo sistêmico. Tem-se a compreensão de que os resultados da socialização organizacional são paulatinamente construídos na co-responsabilidade entre os agentes envolvidos.

Poder nas Organizações, de Paz e cols., aborda o fenômeno do poder organizacional a partir das percepções preponderantes, das dimensões positivas e negativas de poder e dos marcos teóricos, enfocando os componentes das teorias contemporâneas (poder organizacional, poder grupal, poder individual, jogos políticos) e compreendendo o poder como componente da cultura organizacional. Como bem atestam os autores, o fenômeno do poder, por ser multifacetado, apresenta ambigüidades e contradições 
que problematizam sua definição e investigação e acabam por estimular a produção de várias teorias que constroem um panorama da questão.

Diversidade Cultural no Contexto Organizacional, de Torres e Pérez-Nebra, propicia a discussão sistematizada do tema da diversidade cultural. Um modelo de compreensão e uma proposta de avaliação da diversidade organizacional são apresentados e analisados à luz de teorias transculturais de contato intergrupal. São igualmente exploradas as perspectivas do gerenciamento e das pesquisas em diversidade no Brasil. Uma das maiores contribuições do capítulo se deve a um fator externo, mas não alheio ao livro: a psicologia brasileira tem um potencial extraordinário, ainda não reconhecido, de produção de conhecimentos e técnicas sobre a diversidade cultural, porque se estabelece no bojo dos cinco séculos do melting pot brasileiro, cuja diversidade tem sido tão mal administrada ao longo de gerações de cidadãos condenados a estereótipos, discriminações e opressões. No Brasil, gerenciar adequadamente a diversidade cultural, mais do que uma questão de justiça, de aprendizagem ou de lucro, é uma questão de sobrevivência.

Inserção Profissional do Psicólogo em Organizações e no Trabalho, de Zanelli e Bastos contribui para o conhecimento dos focos de trabalho dos psicólogos organizacionais, na perspectiva histórica da construção de campos e sub-campos de atuação relevantes. O capítulo apresenta uma conclusão apropriada para se ter um enfoque contextualizado não apenas das demandas apresentadas ao psicólogo organizacional, mas igualmente do aproveitamento de suas práticas, que têm sido modificadas com o tempo, através da incorporação de novas intervenções e ampliação dos objetivos de determinados trabalhos.

Borges-Andrade e Zanelli, em Psicologia e Produção de Conhecimento em Organizações e Trabalho, identificam a conjuntura teórico-prática referente à produção científica de psicólogos. Tópicos de pesquisa são descritos e analisados por região geográfica e universidade. Descrevem-se, igualmente, os periódicos científicos brasileiros que publicam artigos em Psicologia Organizacional e do Trabalho. Ao concluir o livro, os autores esboçam o futuro da ciência psicológica na conjuntura organizacional, evidenciando a importância da difusão dos conhecimentos gerados pelos resultados da pesquisa em Psicologia para a formação de profissionais capazes de desenvolver medidas e estratégias apropriadas para a solução dos problemas que surgem continuamente nas organizações de trabalho.
Em suma, ao buscar relevância social para o contexto brasileiro, a obra alcança uma adequação maior, em relação à conjuntura latino-americana, do que outras produções redigidas e voltadas para as nações em pleno desenvolvimento econômico. O surgimento desta coletânea vem suprir a carência de divulgação do conhecimento acumulado durante décadas pela Psicologia Organizacional no Brasil, que, ao reverberar na formação de futuros profissionais, promoverá avanços na práxis organizacional e contribuirá para uma sociedade mais justa.

\section{Referências}

Bhaghat, R. S., Kedia, B. L., Harveston, P. D. \& Triandis, H. C. (2002). Cultural variations in the cross-border transfer of organizational knowledge: An integrative framework. The Academy of Management Review, 27(2), 204-221.

Faria, M. F. B. \& Alencar, E. M. L. S. (1996). Estímulos e barreiras à criatividade no ambiente de trabalho. Revista de Administração, 31(2), 50-61.

Schaubroeck, J. \& Lam, S. S. (2002). How similarity to peers and supervisors influences organizational advancement in different cultures. The Academy of Management Journal, 45(6), 1120-1136.

Torres, C. V. \& Ferdman, B. M. (no prelo). American and Brazilian leadership style preferences: A research-based comparison in San Diego and Rio de Janeiro. Journal of Cross-Cultural Psychology.

Van der Vijver, F. J. R. \& Leung, K. (2000). Methodological issues in psychology research on culture. Journal of Cross-Cultural Psychology, 31, 33-51.

Zanelli, J. C., Borges-Andrade, J. E. \& Bastos, A. V. B. (2004). Psicologia, organizações e trabalho no Brasil. Porto Alegre: Artmed. 